\title{
A Comparative Evaluation of Different Gingival Retraction Methods-an In Vivo Study
}

Parul Arora Sachdev ${ }^{1}$, Aman Arora ${ }^{2}$ and Sonia Nanda ${ }^{3 *}$

${ }^{1}$ Department of Prosthodontics, Sudha Rustagi College of Dental Sciences and Research, Faridabad, Haryana, India

${ }^{2}$ Department of Prosthodontics, DAV Dental College, Yamunanagar, Haryana, India

${ }^{3}$ Department of Prosthodontics and Crown and Bridge, National Dental College, Derabassi, Punjab, India

\begin{abstract}
The success of fixed prosthodontic treatment depends upon precision and accuracy in every step involved in the procedure. A very critical aspect of this is making accurate impressions in terms of dimensional accuracy, tear strength etc. The impression materials at the margins of the preparation require substantial thickness in order to resist distortion. This goal is in terms achieved by adequate gingival retraction. This paper focuses on the evaluation of three different gingival retraction methods namely retraction cord, Magic Foam Cord and Expasyl using width and depth of gingival sulcus as criteria.
\end{abstract}

Keywords: Prosthodontic; Materials; Hygroscopic

\section{Introduction}

The field of fixed prosthodontic procedures has seen tremendous improvement over the past decade. The progress has introduced improved procedures and a wide range of materials. Restorations involving fixed partial prosthesis routinely have subgingival margins or finish lines, either for esthetic or functional durability. These preparation finish lines can be exposed by various methods and techniques like mechanical, chemico-mechanical, rotary gingival curettage and electrosurgical methods [1]. Of these four categories, the chemico-mechanical method of gingival retraction is most widely used, where most of the chemical solutions recommended for tissue management are applied with retraction cords.

Gingival retraction reversibly displaces the gingival tissues so that bulk of low viscosity impression material can be introduced in the widened sulcus and the margins can be captured. Gingival tissues are displaced both laterally and vertically. Lateral retraction displaces the tissues and provides adequate bulk of impression material so that it can be removed from the mouth intact with no tearing. Vertical retraction exposes the undercut portion of the tooth apical to the finish line [2].

The critical sulcular width in this regard seems to be approximately $0.15-0.2 \mathrm{~mm}$. A width of less than $0.2 \mathrm{~mm}$ results in impressions that have higher incidences of voids in the marginal area, increase in tearing of the impression material and a reduction in marginal accuracy [3].

The previous studies in literature have analyzed retraction cords and used different chemicals that have been available for long. But now new and different materials have been introduced. The cordless techniques have been introduced with several claimed advantages, such as time savings and enhanced patient comfort while being minimally invasive. Expasyl ${ }^{\oplus}$ (Kerr Corp, Orange, CA, USA) is a paste like gingival retraction material that depends on the haemostatic properties of aluminium chloride and the hygroscopic expansion of kaolin upon contact with the crevicular fluid, to provide mild displacement of the gingiva in about $2 \mathrm{~min}[4]$.

Magic Foam Cord ${ }^{\oplus}$ (Coltene Waldent AG, Altastatten, Switzerland) is an expanding polyvinyl siloxane material designed for easy and fast retraction of the sulcus without the potentially traumatic and timeconsuming packing of retraction cord [5]. Most of the studies on cordless techniques are demonstrations of their clinical use; their effects on the gingival and periodontal tissues are not well documented.
The present study is therefore undertaken to identify the most efficient gingival retraction method out of Expasyl, Magic Foam Cord, and Retraction cord by measuring sulcus width and depth and to determine whether the retraction methods are reversible, leaving no signs of permanent tissue displacement.

\section{Methodology}

\section{Selection of volunteers (inclusion criteria)}

The study was conducted on 18 subjects belonging to the same age group, studying in third year and final year at D.A.V Dental College, Yamunanagar, who volunteered to participate after being fully informed of the nature of investigation. Selection was done based on the following criteria: volunteers belonging to the age group 2025 years with no relevant medical history, non-smoker, having both mandibular premolars bilaterally, gingiva free of any clinical signs of inflammation and attachment loss, teeth free of any signs of periodontal diseases. Mandibular first premolars were used for the purpose of study because premolar teeth offer good visibility and accessibility. Teeth which were attired, tilted, rotated, malalinged, sensitive or carious were not included. The use of unprepared teeth was beneficial, because the effects of preparation and provisionalization steps on the gingival tissues were avoided.

Keeping in mind the code of ethics, as teeth were not prepared, each tooth was subjected to retraction on their buccal aspects only once. Each retraction system was denoted as Expasyl (Kerr Corp.) - E (Figure 1), Magic Foam Cord (Coltene WhaleDent) - M (Figure 2) and Retraction cord - R(Ultradent), (Figure 3)

*Corresponding author: Sonia Nanda, Department of Prosthodontics and Crown and Bridge, National Dental College, Derabassi, Punjab, India, Tel: 8607865955; E-mail: drsonia84@gmail.com

Received: January 06, 2018; Accepted: February 12, 2018; Published: February 16,2018

Citation: Sachdev PA, Arora A, Nanda S (2018) A Comparative Evaluation of Different Gingival Retraction Methods-an in Vivo Study. Oral health case Rep 4 142. doi:10.4172/2471-8726.1000142

Copyright: @ 2018 Sachdev PA, et al. This is an open-access article distributed under the terms of the Creative Commons Attribution License, which permits unrestricted use, distribution, and reproduction in any medium, provided the original author and source are credited. 
Citation: Sachdev PA, Arora A, Nanda S (2018) A Comparative Evaluation of Different Gingival Retraction Methods-an in Vivo Study. Oral health case Rep 4: 142. doi:10.4172/2471-8726.1000142

Page 2 of 7

\section{Making Pre-retraction Impressions and Preparation of Pre-retraction Dies}

Pre-retraction single stage putty wash impression technique was used after selecting tray of proper size. Putty and light body consistency was used. The impressions were poured in high strength die stone. After pouring the impression, the die stone was allowed to set for one hour before it was separated from the impression. Bases of these casts were made in a base former such that they were parallel to the floor with the help of a bubble level.

The casts were sectioned bucco-lingually with the help of a diecutter. Bucco-lingual sectioning was done along the cusp tip of the die to perform the required measurements. This die was kept for measurements and future comparisons with post-operative dies.

\section{Gingival Retraction by the Three Methods}

Gingival retraction was carried out on the selected teeth using the

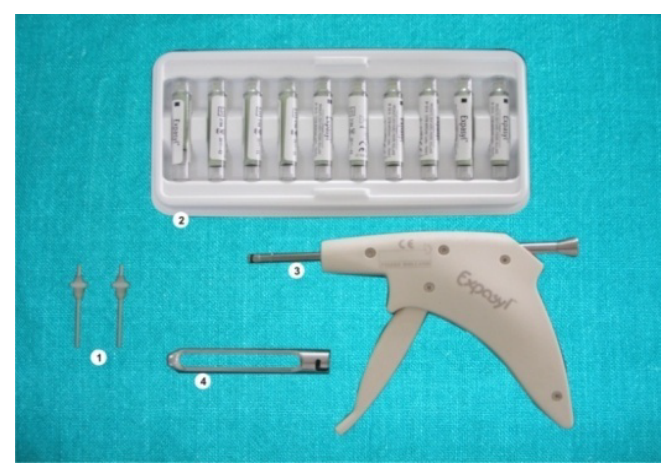

Figure 1: Expasyl retraction material.

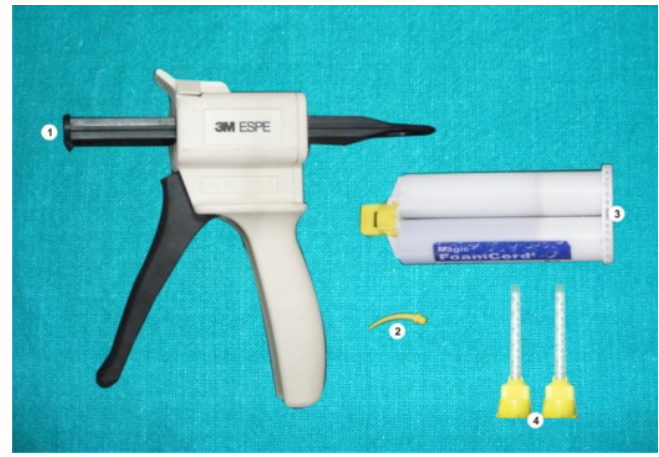

Figure 2: Magic foam cord retraction material.

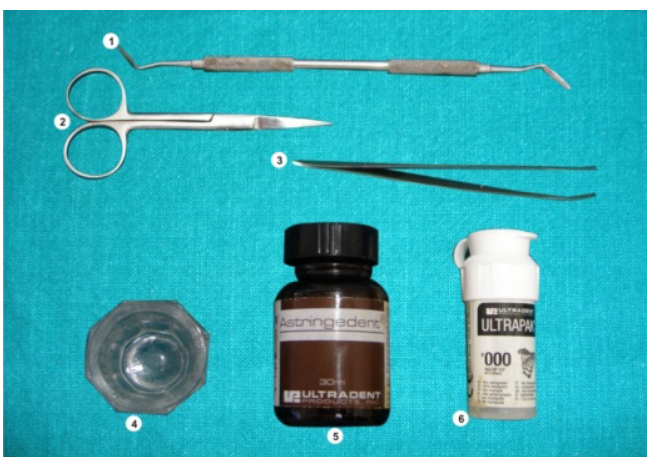

Figure 3: Ultrapak retraction cord and armamentarium for placement.

\begin{tabular}{|c|c|c|}
\hline Volunteer & First Retraction Material & Second Retraction Material \\
\hline 1 & Group E & Group R \\
\hline 2 & Group R & Group M \\
\hline 3 & Group M & Group E \\
\hline 4 & Group E & Group R \\
\hline 5 & Group R & Group M \\
\hline 6 & Group M & Group E \\
\hline 7 & Group E & Group R \\
\hline 8 & Group R & Group M \\
\hline 9 & Group M & Group E \\
\hline 10 & Group E & Group R \\
\hline 11 & Group R & Group M \\
\hline 12 & Group M & Group E \\
\hline 13 & Group E & Group R \\
\hline 14 & Group R & Group M \\
\hline 15 & Group M & Group E \\
\hline 16 & Group E & Group R \\
\hline 17 & Group R & Group M \\
\hline 18 & Group M & Group E \\
\hline
\end{tabular}

Table 1: Grouping of retraction methods for each volunteer.

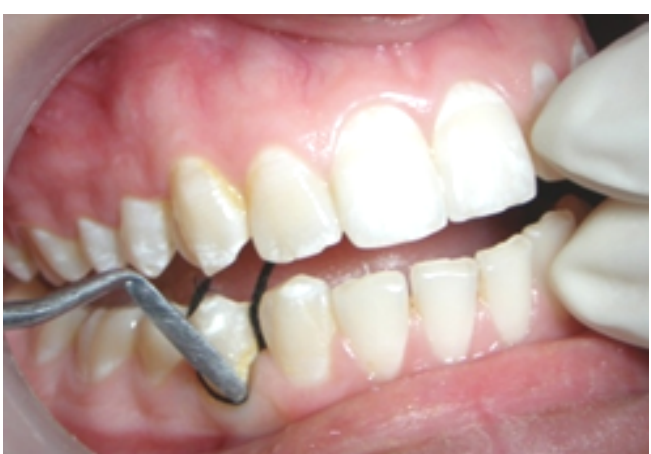

Figure 4: Retraction cord being placed into the buccal gingival sulcus with the help of a cord packer.

three different gingival retraction materials as per the manufacturer's instructions. Since first premolars were used for study, only two materials were used in each volunteer. Each technique was applied to the buccal gingival sulcus along the distance from the mesial to the distal papilla of the selected premolar.

The retraction systems were denoted as Expasyl - E, Magic Foam Cord- $\mathrm{M}$ and Retraction cord- $\mathrm{R}$. Hence, two different retraction materials were used in each volunteer, impressions were made, casts and dies were obtained and grouped as follows (Table 1).

Thus, in a total of 18 volunteers, since only two materials were used in each volunteer, each retraction material was used a total of 12 times. Hence, making $\mathrm{N}=12$ for the study.

\section{Retraction with ultra-Pak cord}

Tissue displacement was preceded with isolation and drying of the area. Appropriate Ultrapak cord size and length was chosen. Since the retraction was done on normal gingiva the smallest available diameter (\#000) of the retraction cord was chosen. It was cut to a length of about 1 inch, wetted in the astringent liquid for 5 minutes. Then it was packed gently in the buccal gingival sulcus with the help of a cord packer. It was kept in the gingival sulcus for not more than 10 minutes [5] (Figure 4).

\section{Retraction with magic foam cord}

Magic Foam Cord can be used with two techniques as specified 
in the manufacturer's instructions. They are (I) The Comprecap Technique and (II) The Putty Technique. In the present study Magic foam cord with putty technique was used. Use of comprecap was not possible in this study because the teeth were unprepared, hence the

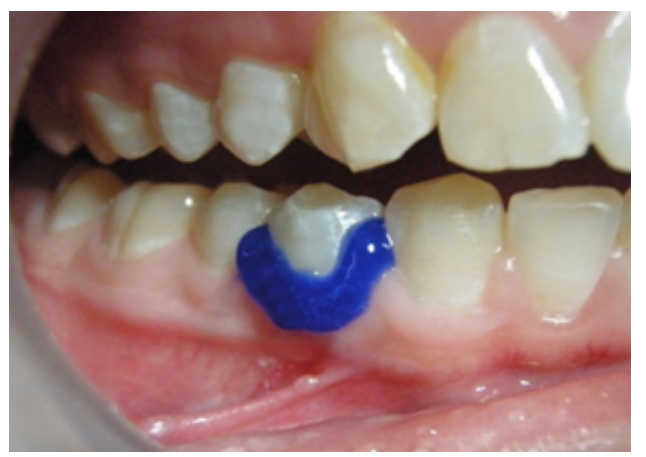

Figure 5: Magic foam cord placed along the buccal gingival sulcus.

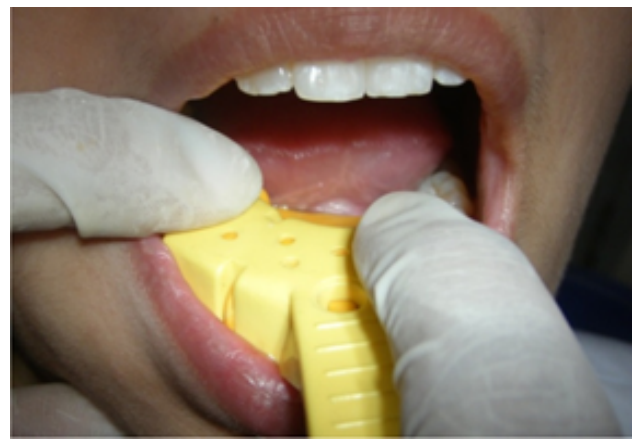

Figure 6: Sectional loaded impression tray positioned.

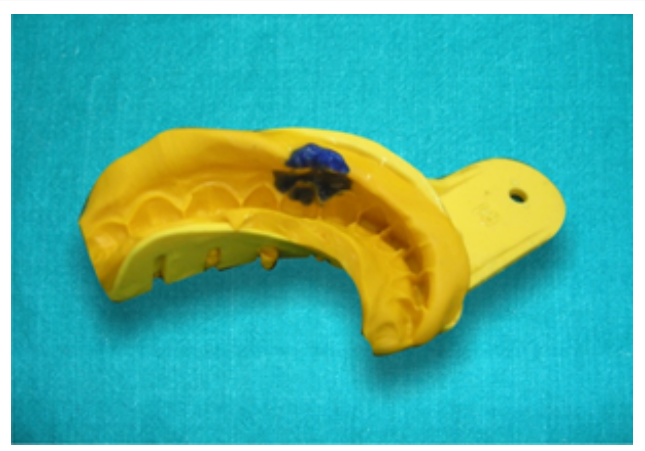

Figure 7: Sectional impression tray removed after 5 minutes.

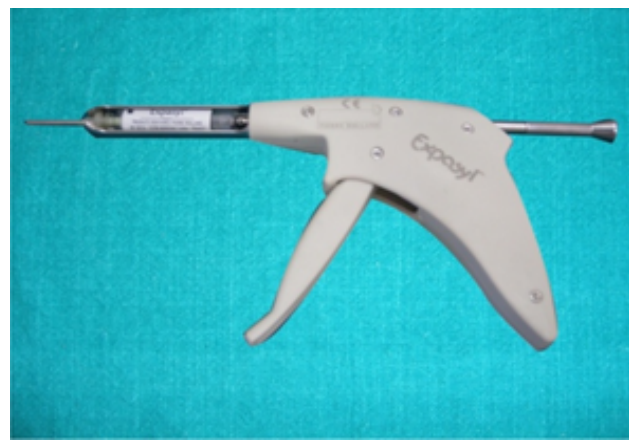

Figure 8: Expasyl retraction material assembled for use.

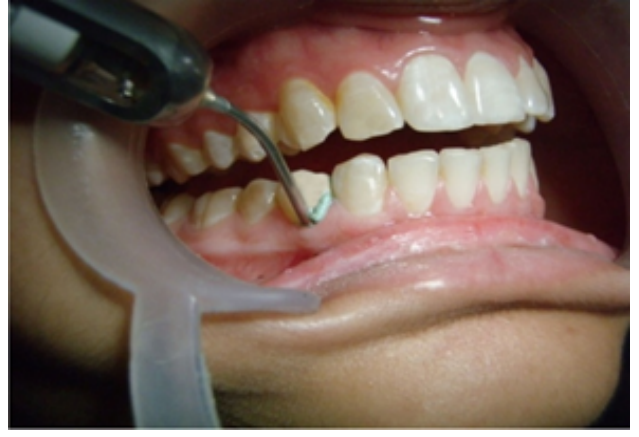

Figure 9: Expasyl injected into the sulcus.

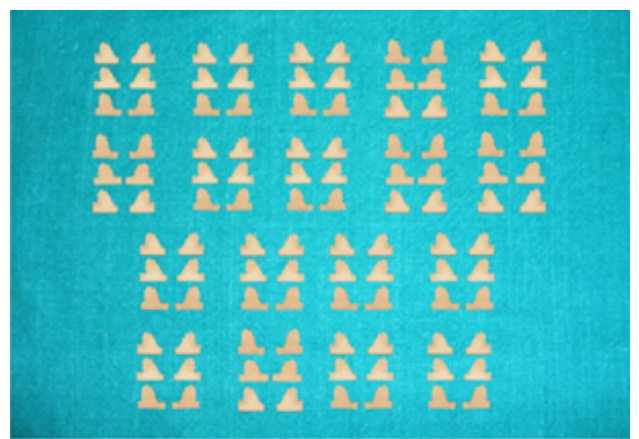

Figure 10: Sectioned dies to carry out measurements.

comprecap would not get fully seated through the intact contact area with the adjacent teeth (Figures 5 and 6).

For the putty technique, tip of the dispensing gun was held perpendicular to the axis of the tooth. An optimum mixture of base and catalyst flow out of the opening was ensured. It was then applied along the crest of buccal marginal gingival. Sectional plastic impression tray was loaded with manipulated putty and positioned in mouth for 5 minutes (Figure 6).

The magic foam material got removed from the sulcus along with the removal of the putty from mouth and resulted in a wide-open sulcus along with a dry field ready to make the impression. (Figure 7).

\section{Retraction with expasyl}

The Expasyl retraction material was assembled according to manufacturer's instructions. The applicator in the form of a metal syringe was used. The cannula was attached to the end of capsule (Figure 8). This was then introduced laterally into the applicator. The cannula was bent to gain easy access to the cervical limit. Pre-bent cannulas can also be used. After that expasyl paste was injected gently into the sulcus, leaning on the tooth at the point of the cervical limit and not on the gingiva, taking care that extremity of the cannula must remain parallel to the axis of the tooth to exert optimal pressure (Figures 8 and 9).

Materials used in each volunteer were removed at the same time; cord was removed manually and Expasyl was removed with copiously irrigated water until no traces of the materials were left.

\section{Making Post-Retraction Impressions and Preparation of Post-Retraction Dies}

After retraction material was removed from the sulcus, single stage putty wash impressions were made as for the pre-retraction dies. 
Citation: Sachdev PA, AroraA, Nanda S (2018) A Comparative Evaluation of Different Gingival Retraction Methods-an in Vivo Study. Oral health case Rep 4: 142. doi:10.4172/2471-8726.1000142

Page 4 of 7

Sectioning of the cast for the first premolar tooth was also done as for the pre-operative dies.

\section{Preparation of Dies to Measure Permanent Tissue Displacement}

After 10 days the volunteers were recalled. Single stage putty wash impressions were again made, casts poured as for the pre-retraction and post-retraction dies.

Hence, 6 dies for each volunteer were made for the purpose of measurements (Figure 10).

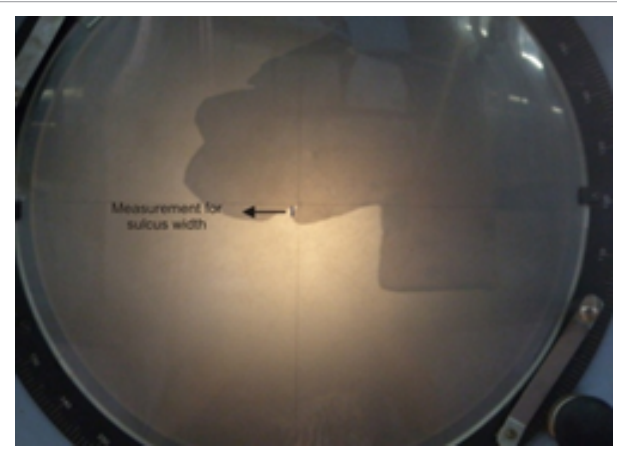

Figure 11: Measuring sulcus width

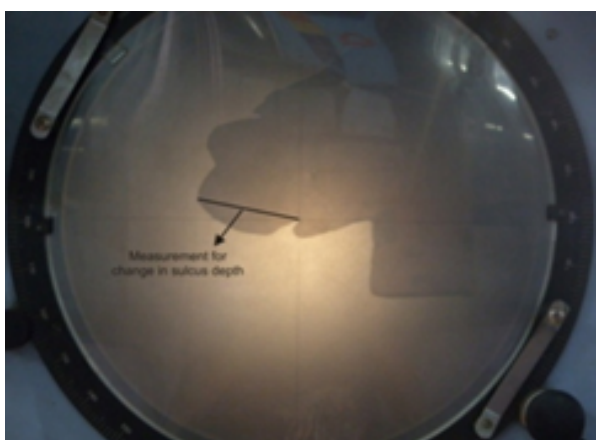

Figure 12: Measurement of change in sulus depth.

\begin{tabular}{|c|c|c|c|}
\hline Retraction methods & $\mathbf{N}$ & Mean $\mathbf{( m m})$ & Standard deviation \\
\hline Retraction cord & 12 & 0.27 & 0.02 \\
\hline Magic Foam Cord & 12 & 0.26 & 0.02 \\
\hline Expasyl & 12 & 0.22 & 0.02 \\
\hline
\end{tabular}

Table 2: Mean change in sulcus width produced by the three retraction methods (Oneway ANOVA test).

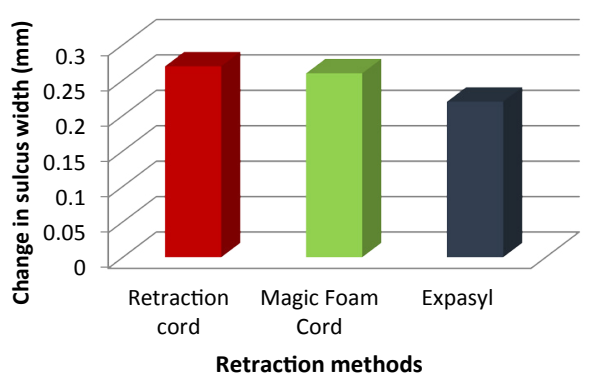

Graph 1: Change in sulcus width produced by retraction cord, magic foam cord and Expasyl.

\begin{tabular}{|l|c|c|c|}
\hline & Retraction method & Comparison group & Level of Significance \\
\cline { 2 - 4 } & Retraction cord & Magic Foam Cord & 1.000 \\
\cline { 2 - 4 } & Expasyl & $<0.0001^{* *}$ \\
\cline { 2 - 4 } $\begin{array}{l}\text { Retraction } \\
\text { produced }\end{array}$ & Magic Foam Cord & Retraction cord & 1.000 \\
\cline { 2 - 4 } & Expasyl & Expasyl & $<0.0001^{* *}$ \\
\cline { 2 - 4 } & Metraction cord & $<0.0001^{* *}$ \\
\hline \multirow{2}{*}{$\begin{array}{l}\text { ** highly significant } \\
\text { (p value at } \leq 0.05 \text { is significant) }\end{array}$} & & $<0.0001^{* *}$ \\
\hline
\end{tabular}

Table 3: Comparison of change in sulcus width obtained by the retraction methods by Post Hoc test.

\section{Testing of Samples}

\section{Measuring sulcus width}

Width of the sulcus was measured on the sectioned dies by using a Profile Projector which has axis (X-Y axis) to carryout various measurements. Width of the retracted gingival sulcus is the distance between the crest of the marginal gingiva and tooth surface [6]. The value so obtained was recorded and compared with the width of the sulcus in the pre-retraction dies. All the values so recorded were kept for future references (Figure 11).

\section{Measurement of change in sulcus depth}

Change in sulcus depth on the sectioned dies was measured as the distance between the tip of cusp to the deepest point of the gingival sulcus by using a Profile Projector which has an axis to carryout measurements. This was measured on the pre-retraction dies and compared with the sulcus depth in the post-retraction dies. Comparison of different retraction materials for change in sulcus depth was carried out (Figure 12).

\section{Measuring permanent tissue displacement}

The change in depth of sulcus was measured in the 10 days post retraction dies. The obtained values were then compared with the value of depth of the sulcus in the pre-operative unretracted dies. The difference in the values indicated the amount of permanent tissue displacement or recession produced by different gingival retraction methods.

\section{Results}

It was observed that the mean change in sulcus width obtained for the impregnated retraction cord was 0.271 with a standard deviation of 0.02 , that for Magic Foam Cord was 0.260 with a standard deviation of 0.02 , and that for Expasyl was 0.22 with a standard deviation of 0.02 by Oneway ANOVA test (Table 2 and Graph 1)

The values were further subjected to post hoc test for multiple comparisons and no statistical difference was observed between the retraction width produced by retraction cord and magic foam cord. The retraction width produced by Expasyl was less and the difference was clinically significant with retraction cord and magic foam cord (Table 3). The "p" values were considered significant at or below 0.05 .

The observations were further subjected to Wilcoxons signed ranks test and Paired t-test to find out whether the change in width produced is in range of clinical significance (Table 4). It was inferred that the effect produced with all the three agents gave statistically significant results in terms of retraction produced in width.

Maximum change in sulcus depth was produced by retraction cord with a mean of 0.299 and a standard deviation of 0.04 followed 
Citation: Sachdev PA, AroraA, Nanda S (2018) A Comparative Evaluation of Different Gingival Retraction Methods-an in Vivo Study. Oral health case Rep 4: 142. doi:10.4172/2471-8726.1000142

Page 5 of 7

by Magic Foam Cord 0.231 and a standard deviation of 0.04 and then Expasyl 0.195 , standard deviation 0.04 by Oneway ANOVA test as presented in the Table 5 and Graph 2.

Oneway ANOVA test was followed by Post Hoc test for multiple comparisons and it was observed that the comparison of change in sulcus depth produced by retraction cord was highly significant as compared to both the other methods. Also, there is no difference between the change in sulcus depth produced by Magic Foam Cord and Expasyl and the difference was statistically insignificant (Table 6).

It was also inferred from Wilkoxon Signed ranks test and Paired

\begin{tabular}{|c|c|}
\hline Retraction methods & $\begin{array}{c}\text { Significance of change in width produced (pre- } \\
\text { retraction to post retraction) }\end{array}$ \\
\hline Retraction cord & $<0.002^{* *}$ \\
\hline Magic Foam Cord & $<0.002^{* *}$ \\
\hline Expasyl & $<0.002^{* *}$ \\
\hline **highly significant (p value $\leq 0.05$ is significant) \\
\hline
\end{tabular}

Table 4: Level of significance of change in width (in $\mathrm{mm}$ ) produced by Wilcoxons signed ranks test and Paired t-test.

\begin{tabular}{|c|c|c|c|}
\hline Retraction methods & $\mathbf{N}$ & Mean $\mathbf{( m m})$ & Standard deviation \\
\hline Retraction cord & 12 & 0.299 & 0.04 \\
\hline Magic Foam Cord & 12 & 0.231 & 0.04 \\
\hline Expasyl & 12 & 0.195 & 0.04 \\
\hline
\end{tabular}

Table 5: Mean change in depth produced by the three retraction methods by ANOVA test.

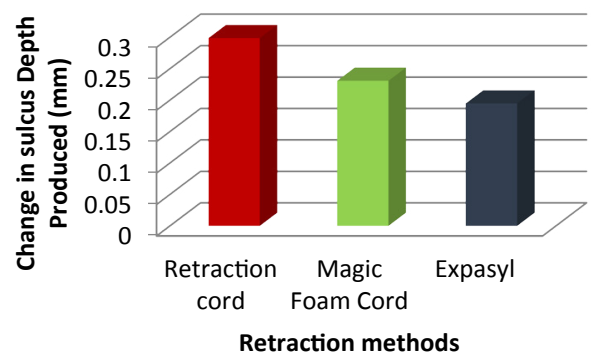

Graph 2: Change in sulcus depth produced by retraction cord, magic foam cord and Expasyl.

\begin{tabular}{|c|c|c|c|}
\hline \multirow{7}{*}{$\begin{array}{l}\text { Change in sulcus } \\
\text { depth produced }\end{array}$} & Retraction method & Comparison group & $\begin{array}{c}\text { Level of } \\
\text { significance }\end{array}$ \\
\hline & \multirow{2}{*}{ Retraction cord } & Magic Foam Cord & $<0.002^{* *}$ \\
\hline & & Expasyl & $<0.001^{* *}$ \\
\hline & \multirow{2}{*}{ Magic Foam Cord } & Retraction cord & $<0.002^{* *}$ \\
\hline & & Expasyl & 0.165 \\
\hline & \multirow{2}{*}{ Expasyl } & Retraction cord & $<0.001^{* *}$ \\
\hline & & Magic Foam Cord & 0.165 \\
\hline
\end{tabular}

Table 6: Comparison of change in sulcus depth obtained by retraction methods by Post Hoc test.

\begin{tabular}{|c|c|}
\hline Retraction method & $\begin{array}{c}\text { Significance of change in depth produced (pre- } \\
\text { retraction to post retraction) }\end{array}$ \\
\hline Retraction cord & $<0.002^{* *}$ \\
\hline Magic Foam Cord & $<0.002^{* *}$ \\
\hline Expasyl & $<0.002^{* *}$ \\
\hline **highly significant \\
(p value $\leq 0.05$ is significant)
\end{tabular}

Table 7: Level of significance of change in depth produced by Wilkoxon Singed ranks test and paired t-test.

\begin{tabular}{|c|c|c|c|}
\hline Retraction methods & $\mathbf{N}$ & Mean $\mathbf{( m m})$ & Standard deviation \\
\hline Retraction cord & 12 & 0.124 & 0.03 \\
\hline Magic Foam Cord & 12 & 0.090 & 0.03 \\
\hline Expasyl & 12 & 0.080 & 0.03 \\
\hline
\end{tabular}

Table 8: Mean change in sulcus depth in 10 days post retraction dies as produced by the three retraction methods (pre-retraction and 10 days post retraction dies) by ANOVA test.

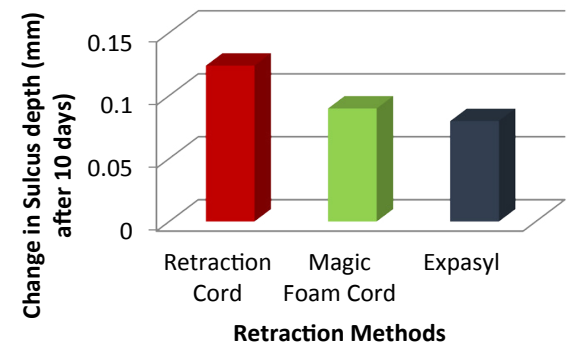

Graph 3: Mean change in sulcus depth in 10 days post retraction dies for measuring permanent tissue displacement.

\begin{tabular}{|c|c|}
\hline Retraction methods & $\begin{array}{c}\text { Significance of change in depth produced (pre- } \\
\text { retraction to } \mathbf{1 0} \text { days post retraction) }\end{array}$ \\
\hline Retraction cord & $0.052^{*}$ \\
\hline Magic Foam Cord & $0.075^{\star}$ \\
\hline Expasyl & $0.077^{*}$ \\
\hline${ }^{*}$ Not significant \\
(p value at or below 0.05 is significant)
\end{tabular}

Table 9: Level of significance of change in depth (in $\mathrm{mm}$ ) in 10 days post retraction dies by Wilkoxons Signed ranks test.

T-test that clinically significant change in sulcus depth was produced by all the three retraction agents with the level of significance as 0.002 . (The mean difference was significant at 0.05) (Table 7).

For the third parameter of the study i.e any signs of permanent tissue displacement, the data was collected by measuring the change in sulcus depth in dies obtained by making impressions after 10 days of retraction. The data is tabulated and is presented as mean and standard deviation. ANOVA test was performed for calculating mean change in sulcus depth in ten days (Table 8) (Graph 3).

The difference in the depth between pre-retraction and 10 days post-retraction dies was clinically insignificant as presented by Wilcoxons Signed ranks test (Table 9).

Thus, concluding that none of the retraction agents produced any signs of permanent tissue displacement.

\section{Discussion}

The cordless techniques for gingival retraction have been introduced with several claimed advantages like time-saving and enhanced patient comfort while being minimally invasive. Expasyl ${ }^{\oplus}$ (Kerr Corp., Orange, CA, USA) is a paste like gingival retraction material that depends on the haemostatic properties of aluminium chloride and the hygroscopic expansion of kaolin upon contact with the crevicular fluid, to provide mild displacement of the gingiva in about 2 minutes. Aluminum chloride has well known astringent properties. Aluminium chloride leads to protein coagulation on the surface of the tissue [4]. When the paste is applied within the sulcus, it develops pressure of $0.1 \mathrm{~N} / \mathrm{mm}^{2}$ and the gingival crest is sufficiently detached to allow an impression to be taken without injuring the epithelial attachment. It is found by experimental studies that it has good antimicrobial efficacy and biocompatibility with the tissues [7]. 
Magic Foam Cord ${ }^{\circledR}$ (Coltene Waldent AG, Altstatten, Switzerland), as suggested by the manufacturer, is an expanding polyvinylsiloxane material designed for easy and fast retraction of the sulcus without the potentially traumatic and time-consuming packing of the retraction cords into the sulcus [5]. Due to the counter pressure of the comprecaps or the putty index, the expansion of Magic foam occurs within the sulcus. The manufacturers claim that Magic Foam Cord expands in the sulcus. It is easy to handle, time-saving, painless to the patient, provides wide open sulcus without invasive techniques or materials, astringent is not required, no need to rinse and more efficient- when using on multiple teeth.

The Magic Foam Cord was potentially less traumatic as controlled pressure through comprecap was used, whereas expasyl was least traumatic and induced no bleeding as it contains aluminum chloride an astringent paste in its composition [8].

Expasyl is a non-cord "mechanico-chemical" method of gingival displacement where the material is placed into the gingival sulcus with no pressure. Hence the amount of retraction observed may be less. It might be more effective under specific, limited conditions-when the sulcus is flexible and of sufficient depth. The magic foam cord is a "mechanical" gingival retraction system consisting of expanding type polyvinyl siloxane material. Hence, it might be the reason for getting better retraction from magic foam cord compared to expasyl retraction system [9].

In the present study we observed that the retraction produced by retraction cord was higher as compared to Expasyl and magic foam cord. Both the cordless systems were convenient to use. Similar results were obtained in a study that Expasly and Magic Foam cord retraction system were found easier in placement compared to retraction cord. The retraction produced by retraction cord was higher as the cord was pushed mechanically into the gingival sulcus [9].

In the present study it was observed that all the three retraction materials used achieved a sulcus width of $0.27 \mathrm{~mm}, 0.26 \mathrm{~mm}$ and 0.22 $\mathrm{mm}$ for Retraction cord, Magic foam and Expasyl respectively. These values correspond to the critical sulcular width of $0.2 \mathrm{~mm}$ at the level of finish line. The Impressions with less sulcular width have higher incidents of distortion, voids, tearing of impression material, and reduction in marginal accuracy. This critical width of $0.2 \mathrm{~mm}$ of the displaced sulcus has been achieved by all the three retraction agents compared in our study.

Another inference drawn in our study was that the effect produced with all the three methods used gave statistically significant results in terms of retraction produced in width and depth. A study by Yang et al. involved two cordless techniques: Expasyl paste and Korlex-GR ${ }^{\circ}$ (Biotech-one, San-chung, Tiwan) and compared them with Ultrapak ${ }^{\circ}$ cords (Ultrapak Products Inc., South Jordan, Utah). The authors reported significant gingival deflection by all the three agents but the use of Ultrapak appeared more painful and produced more gingival recession than cordless techniques [10].

Yet another finding of the present study is that some amount of permanent tissue displacement was observed with the use of retraction cord. The gingival recession observed was in terms of change in sulcus depth, but it was clinically insignificant compared to the pre-retraction sulcus. A study performed in the past had also inferred that the use of Ultrapak retraction cord appeared to produce more gingival recession than cordless techniques. The recession observed in cordless technique was too small and clinically insignificant [10].
To add on, it was observed that clinical handling of retraction cord was a tedious process and caused some amount of pain or discomfort to the volunteers on application. Magic Foam cord proved equally effective, less discomforting and traumatic to the gingival. Hence, it was rated as a better retraction material. This was also inferred in the past studies because in order to insert the retraction cord into the gingival sulcus, concentrated mechanical pressure applied to the delicate gingival tissue is almost clinically unavoidable. The results indicated that the use of the medicated cord was more painful than the injection types. This result confirmed the clinical convenience and comfort of injection-type retraction materials [10].

In a study on gingival inflammation by De Gennaro et al. it was concluded that the use of retraction cord can be laborious, timeconsuming, can cause gingival bleeding, uncomforTable for patients in the absence of anesthesia and when inappropriately manipulated, can lead to direct injury and gingival recession [11].

Another finding in the present study was that the average permanent tissue displacement caused by retraction cord was 0.124 $\mathrm{mm}$. A previous study had also reported that gingival retraction with cord caused destruction of the junctional epithelium that took 8 days to heal and caused gingival recession of about $0.2-0.1 \mathrm{~mm}$ [12].

Through clinical and statistical analysis, we could infer that all three test materials used in this study achieved adequate gingival displacement. The material which is least traumatic to the tissues ranks better. When compared to the gingival retraction cord, Magic Foam Cord ranks as a better retraction material because it provides near equivalent horizontal and vertical displacement and almost complete recovery of the sulcular depth in ten days assigned for this study, with less patient discomfort. Expasyl, on the other hand produced less gingival displacement in terms of width and depth when compared to Ultrapak retraction cord and Magic Foam. Cord packing procedures have a potential to cause detachment of the sulcular epithelium and induce bleeding. In contrast, application of Magic Foam was easy with less trauma to the sulcular tissues.

This study investigated the effectiveness of the retraction methods on gingival displacement and not on the gingival and periodontal health like inflammatory changes. Also, the effect was not studied in presence of blood, traces of which can be present after tooth preparation or in case of inflamed gingiva. Since, the retraction materials were applied to structurally healthy teeth, in which no crown preparation was done, one can argue that the results could not be extrapolated to clinical reality.

\section{Conclusion}

Within the limitations of this study the following conclusions were drawn:

- All the three retraction methods-Retraction cord, Magic Foam Cord and Expasyl employed in this study achieved adequate sulcus width and depth.

- Retraction cord was the most effective method of gingival retraction in terms of both sulcus width and depth but in terms of ease of clinical handling Magic Form Cord is a better material.

- Statistical analysis for sulcus width resulted in a statistically insignificant difference between the retraction produced by Retraction cord and Magic Foam Cord. The retraction produced by Expasyl was less and the difference was clinically significant compared to the other two. 
Citation: Sachdev PA, AroraA, Nanda S (2018) A Comparative Evaluation of Different Gingival Retraction Methods-an in Vivo Study. Oral health case Rep 4: 142. doi:10.4172/2471-8726.1000142

Page 7 of 7

- Statistical analysis for sulcus depth resulted in a statistically significant change in sulcus depth produced by Retraction cord compared to Magic Foam Cord and Expasyl. The comparison of the effect of Magic Foam Cord and Expasyl for sulcus depth was not clinically significant.

- Also, statistical analysis for permanent tissue displacement showed clinically insignificant results hence none of the retraction agents produced any signs of permanent tissue displacement.

\section{References}

1. Benson BW, Bomberg TJ, Hatch RA, Hoffman W (1986) Tissue displacement methods in fixed prosthodontics. J Prosthet Dent 55: 175-181.

2. Bowles WH, Tardy SJ, Vahadi A (1991) Evaluation of new gingival retraction agents. J Dent Res 70: 1447-1449.

3. Baharav H, Kupershmidt I, Laufer BZ, Cardash HS (2004) The effect of sulcular width on the linear accuracy of impression materials in the presence of an undercut. Int J Prosthodont 17: 585-589.

4. Lesage $P$ (2002) Expasyl: Protocol for use with fixed prosthodontics. Clinic 23: 97-103.
5. Hamad Al, Azar WZ, Alwaeli HA, Said KN (2008) A clinical study on the effects of cordless and conventional retraction techniques on the gingival and periodontal health. J Clin Periodontol 35: 1053-1058.

6. Raghav D, Singh S, Zaheer Kola M, Hussain Shah A (2014) A comparative clinical and quantitative evaluation of the efficacy of conventional and recent gingival retraction systems: An in vitro study. Eur J Prosthodont 2: 76-81.

7. Christopher CK Ho (2007) Making great impressions. Australasian Dent Pract 2: $140-142$.

8. Donovan TE, Chee WW (2004) Current concepts in gingival displacement. Dent Clin North Am 48: 433-444.

9. Gupta A, Prithviraj DR, Gupta D, Shruti D (2013) Clinical evaluation of three new gingival retraction systems: a research report. J Indian Prosthodont Soc 13: $36-42$.

10. Yang JC, Tsai CM, Chen MS, Wei JY (2005) Clinical study of newly developed injection type gingival retraction materials. Chinese Dent J 24: 147-151.

11. Gennaro DE, Calhoun $L$ (1982) A comparison of gingival inflammation related to retraction cords. J Prosthet Dent 47: 384-386.

12. Ruel J, Schuessler PJ (1980) Effect of retraction procedures on the periodontium in humans. J Prosthet Dent 44: 508-515. 